Sorting on the Used-Car Market After the Volkswagen Emission Scandal

Anthony Strittmatter, Michael Lechner

May 2017 Discussion Paper no. 2017-06

School of Economics and Political Science,

University of St. Gallen

Department of Economics 


$\begin{array}{ll}\text { Editor: } & \text { Martina Flockerzi } \\ & \text { University of St.Gallen } \\ & \text { School of Economics and Political Science } \\ & \text { Department of Economics } \\ & \text { Müller-Friedberg-Strasse 6/8 } \\ & \text { CH-9000 St. Gallen } \\ & \text { Phone +41 71 224 23 25 } \\ & \text { Email seps@unisg.ch } \\ & \text { School of Economics and Political Science } \\ & \text { Department of Economics } \\ & \text { University of St.Gallen } \\ \text { Publisher: } & \text { Müller-Friedberg-Strasse 6/8 } \\ & \text { CH-9000 St. Gallen } \\ & \text { Phone +41 71 224 23 25 } \\ & \text { http://www.seps.unisg.ch }\end{array}$




\title{
Sorting on the Used-Car Market After the Volkswagen Emission Scandal ${ }^{1}$
}

\author{
Anthony Strittmatter and Michael Lechner ${ }^{2}$
}

Author's address:

Anthony Strittmatter, Ph.D.

Swiss Institute for Empirical Economic Research (SEW)

Varnbüelstr. 14

$\mathrm{CH}-9000$ St. Gallen

Phone +41712242305

Fax $\quad+41712242302$

Email Anthony.strittmatter@unisg.ch

Website www.anthonystrittmatter.com

Michael Lechner

Swiss Institute for Empirical Economic Research (SEW)

Varnbüelstr. 14

$\mathrm{CH}-9000$ St. Gallen

Phone +41712242814

Fax $\quad+41712242302$

Email Michael.lechner@unisg.ch

Website www.michael-lechner.eu

\footnotetext{
${ }^{1}$ We benefitted from comment by Stefan Bühler, Nicolas Eschenbaum, and Philipp Zahn. We are indebted to Andreas Hermann and Benjamin Polak for their data provision and support. The usual disclaimer applies.

${ }^{2}$ Michael Lechner is also affiliated with CEPR and PSI, London, CESIfo, Munich, IAB, Nuremberg, and IZA, Bonn.
} 


\begin{abstract}
The disclosure of the VW emission manipulation scandal caused a quasi-experimental market shock in the observable quality of VW diesel vehicles. We consider a classical model for adverse selection and sorting to derive an empirically testable hypothesis about the impact of observable quality on the supply of used cars. We test the hypothesis with data collected from an online car selling platform which reflects about $50 \%$ of the German used-car market. The empirical approach is based on a conditional difference-in-differences method. We find that the supply of used VW diesel vehicles increases after the VW emission scandal. This finding is consistent with the predictions of the theoretical model. Furthermore, we find the positive supply effects increase with the probability of manipulation.
\end{abstract}

\title{
Keywords
}

Supply of used cars, quality of durable goods, sorting, difference-in-differences, management fraud.

\section{JEL Classification}

D82, L15, L62. 


\section{Introduction}

Asymmetric information between potential used-car sellers and buyers is widely acknowledged (e.g., Akerlof, 1970). It is often assumed that the quality of some car components is observable for potential used-car sellers and buyers. However, the quality of other car components is only observable for potential used-car sellers and unobservable for potential used-car buyers. This may lead to adverse selection, which implies owners of used cars with high unobservable quality have little incentives to bring their cars to the market, because the high unobservable quality would not be rewarded with high transaction prices. Sorting could be a motive for trade of used cars with high unobservable quality when individuals have heterogeneous preferences for quality (e.g., Hendel and Lizzeri, 1999). Car owners with high preference for quality could sell their cars at a discount to individuals with low preference for quality. Even when the unobservable car quality is high, the utility of trade could be positive for potential sellers (and buyers) when the observable quality is low. The sorting motive possibly dilutes adverse selection when the observed car quality is declining.

The plausibility of the sorting mechanism depends on the way how potential buyers form their expectations about the unobservable used-car quality. Certainly, the observable usedcar quality influences buyers' expectations about unobservable used-car quality (e.g., Stiglitz, 1987). Theoretical work by Hendel and Lizzeri (2002) and Peterson and Schneider (2016) propose a negative correlation between the observable quality and expectations about unobservable quality of traded cars. They assume buyers are aware of the sorting mechanism and have rational expectations about the unobservable quality of traded cars. When the observable used-car quality is high, then potential buyers expect low unobservable quality, because otherwise potential sellers have no sorting motive. However, when the observable used-car quality is low, then buyers anticipate sorting motives no matter whether the unobservable quality is low or high. Peterson and Schneider's (2016) model predicts the sorting 
mechanism dominates the adverse selection mechanism when the observable used-car quality decreases. This implies a decline in the observable used-car quality increases the supply probability. This theoretical prediction is difficult to test empirically, because usually we are unable to observe exogenous variation in observable used-car quality (a noticeable exception is Tadelis and Zettelmeyer, 2015).

In this study, we exploit the decline in the observed quality of Volkswagen (VW) diesel cars after the disclosure of the stunning VW emission scandal to test empirically Peterson and Schneider's (2016) theoretical prediction. On September 18, 2015, the US Environmental Protection Agency (EPA) disclosed the installation of defeat device software in the emission control system of VW diesel engines (EPA, 2015). This disclosure lowers the observable quality of VW diesel cars, because the defeat device negatively affects the environmental and engine performance of the manipulated cars. Furthermore, the durability of several parts of the exhaust system (e.g., the catalytic converter) could significantly decline after possible retrofitting thus increasing maintenance costs. Since the information revealed by this disclosure was not expected by market participants, the resulting decline in observable car quality is a quasi-experimental exogenous shock to the used-car market. Thus, the VW emission scandal enables the investigation of an empirically testable implication of Peterson and Schneider's (2016) model with high credibility.

Our analyses are based on data collected from a large German online car advertisement portal. The volume of this online market is approximately 3.6 million cars per year, which reflects a trade value of 40 billion Euros per year or $50 \%$ of the German used-car market. ${ }^{1}$ Our sample contains 1.1 million newly offered cars between August 2015 and April 2016. Furthermore, we observe detailed car and seller characteristics. We employ difference-in-

1 The German Federal Motor Transport Authority (Kraftfahtbundesamt) documents 3.2 million first-time registered cars and 7.3 million ownership transformation of cars during the year 2014 (Kraftfahtbundesamt, 2015a, 2015b). 
differences estimators to investigate the market shares of diesel cars by carmakers and time period before and after the disclosure. In particular, we use unconditional and conditional differences-in-differences estimators. In the latter approach, we account for important variables that could affect the structure of the used-car market. For this purpose, we use semi-parametric radius matching estimators with bias adjustment (Lechner, Miquel, and Wunsch, 2011).

We find that the supply of used VW diesel cars increases significantly after the disclosure of the emission manipulation scandal. This confirms the implications of Peterson and Schneider's (2016) model for adverse selection and sorting in durable goods markets with asymmetric information. We provide evidence that these results are strongly driven by the supply of minivans and Sport Utility Vehicles (SUVs). Both vehicle classes are heavy polluters. Furthermore, we provide evidence that the positive supply effects increase with the probability of manipulation and that spillover effects to unmanipulated VW diesel cars do not explain an increase in supply. This suggests that owners of used VW diesel cars without a defeat device do not update their expectations about future revelations of emission manipulation. Finally, we show that mainly professional car dealers who do not offer a warranty increase their supply of VW diesel vehicles after the disclosure of the VW emission scandal. This suggests trade reactions to product quality fraud. However, Guajardo, Cohen, and Netessine (2016) propose that the omission of warranties together with the decrement in product quality could disproportionately decrease demand.

In the next section, we review the most related literature. In Section 3, we introduce the background of the VW emission scandal. In Section 4, we review the model for adverse selection and sorting. In Section 5, we describe the data. In Section 6, we report the empirical results. The final section concludes the discussion. We provide additional proofs and descriptive statistics in Online Appendices A-E. ${ }^{2}$

2 The Online Appendices are available at www.anthonystrittmatter.com. 


\section{Related Literature}

The empirical evidence for adverse selection in durable goods markets is mixed. Adam, Hosken, and Newberry (2011) and Bond (1982) find no empirical evidence for adverse selection. Bond (1984), Emons and Sheldon (2009), Engers, Hartman, and Stern (2009), Genesove (1993), and Gillian (2004) find evidence for adverse selection (mainly for older products and private sellers), but not along all dimensions of their empirical analyses. The literature widely recognises institutions (e.g., warranties, reputation) as one factor limiting adverse selection. Lewis (2011) shows that the disclosure of seller information can lower the level of adverse selection in used-car online auctions. Hendel and Lizzeri (2002), Johnson, Schneider, and Waldman (2014) and Johnson and Waldman (2003) suggest that leasing instead of buying a car can limit the amount of adverse selection.

Peterson and Schneider (2014) propose the notion of heterogeneous adverse selection with respect to the quality of different car components. They investigate the defect probability of different car components and the corresponding turnover rates for different car models. Components with high probability of an undetectable defect lower the turnover rates of cars. This is evidence for adverse selection. Moreover, components with high probability of an easily detectable defect increase the turnover rates of cars. This is evidence for sorting with respect to car quality. In a similar endeavour, Peterson and Schneider (2016) find a negative relation between prices and observable car damages, but a positive relation between prices and unobservable car damages. They argue that the combination of adverse selection and sorting can explain several observed trade patterns. Our results support this conception.

Tadelis and Zettelmeyer (2015) investigate the random disclosure of information about the quality of used-cars during online auctions. The surprising disclosure of new information increases the sales probability and revenues of sellers, no matter whether the disclosed information increases or decreases the observable quality. They argue the sorting of bidders 
with heterogenous quality preferences increases the competition, even if the new information reveals low quality. We complement their results by analysing supply side reactions to the disclosure of used-car quality in an online advertisement portal. ${ }^{3}$

This study is also related to the literature on management fraud. This literature is successful in documenting the reputational costs and financial market reactions associated with the disclosure of management fraud, but little is known about supply reactions to the revelation of product quality fraud. ${ }^{4}$ For example, Gianetti and Wang (2016) show that households reduce their stock market holdings in both fraudulent and non-fraudulent firms after the disclosure of corporate security frauds. The latter suggests that households update their expectations about future revelations of fraud. To some extent, the monetary consequences of corporate security fraud are applicable to product quality fraud. However, we document only selective trade reactions after disclosure of the VW emission scandal, which do not spread to unmanipulated cars. This suggests the supply side reactions to quality fraud in durable goods markets are narrow (as opposed to the widespread financial market reactions documented in Gianetti and Wang, 2016). In a somewhat related study, Karpoff, Lott, and Wherly (2005) find only small reputational penalties when companies violate environmental regulations.

\section{The VW emission scandal}

Many countries use emission standards to limit toxic and greenhouse gases in automobile exhausts. In Germany, the emission standards of the European Commission (Euro 1-6) have limited nitrogen oxide (NOx) emissions since 1992 (European Commission, 1991). The Euro 3

\footnotetext{
3 Jin and Leslie (2003) show market reactions to the hygiene quality disclosure of restaurants.

4 Alexander (1999) characterises reputational penalties and market-based sanction after public corporations commit crimes. Johnson, Xie, and Yi (2014) document an increase of operational costs of fraudulent firms, because the costs of selling increase. Luca and Zervas (2016) investigate customer review fraud in online recommendation platforms. Gande and Lewis (2009) find negative stock price reaction to shareholder-initiated lawsuits. Palmrose, Richardson, and Scholz (2004) find negative abnormal returns after financial restatements which involve fraud.
} 
emission standard limits nitrogen oxide emissions of diesel cars to $0.5 \mathrm{~g} / \mathrm{km} .^{5}$ This limit was lowered to $0.25 \mathrm{~g} / \mathrm{km}$ in January 2005 (Euro 4), $0.18 \mathrm{~g} / \mathrm{km}$ in September 2009 (Euro 5), and $0.08 \mathrm{~g} / \mathrm{km}$ in September 2014 (Euro 6). New regulations apply only to newly registered cars after the implementation date (European Commission, 2007).

In the US, the EPA and the California Air Resources Board (CARB) regulate automobile exhausts. Each state can choose to adopt either the EPA or CARB emission standards. The nitrogen oxide emission limits are much lower in the US than in the EU. ${ }^{6}$ The EPA Tier 2 standard was phased-in between 2004 and 2009. The average nitrogen oxide emission limits of the entire vehicle fleet sold by a certain car manufacturer were ultimately set at $0.07 \mathrm{~g} / \mathrm{mile}$ (Cook, McArdle, Warner, 2006). ${ }^{7}$ The CARB Low Emission Vehicle II (LEV II) standard was phased-in between 2004 and 2010. Nitrogen oxide emissions limits were ultimately set at between $0.05-0.1 \mathrm{~g} / \mathrm{mile}$, depending on the durability of the car (Cook, McArdle, Warner, 2006). ${ }^{8}$

In 2007, the VW engine EA 189 was the first diesel engine that was certified under the EPA Tier 2 (Bin 5) and CARB LEV II emission standards. The engine achieved low nitrogen emissions by employing a nitrogen oxide storage catalytic converter (see Yang et al., 2015, for details). The nitrogen oxide storage catalytic converter stores nitrogen oxide in a catalyst material (often barium) and converts it into nitrogen (N2) and carbon dioxide (CO2). The conversion process requires the injection of additional fuel to regenerate the catalytic converter,

\footnotetext{
5 The introduction of the Euro 3 emission standard in January 2000 directly limited nitrogen oxide emissions for the first time (previously the limits were combined with the carbon-hydrogen emission). The nitrogen oxide emission limits are higher for cars with diesel than with gasoline engines.

6 US emission standard do not distinguish between cars with diesel and gasoline engine.

7 Under the EPA Tier 3 emission standard, the combined non-methane organic gas and nitrogen oxide average emission of the fleet must be below $0.03 \mathrm{~g} / \mathrm{mile}$ by 2025 .

8 The new LEV III is being phased-in between 2015 and 2025. The combined limits for non-methane organic gas and nitrogen oxide will ultimately reach $0.02 \mathrm{~g} /$ mile in 2020. Additionally, the CARB awards the certificates Ultra Low Emission Vehicles (ULEV) and Super Ultra Low Emission Vehicles (SULEV) to cars with very low emissions.
} 
which increases fuel consumption. The nitrogen oxide storage catalytic converter has low durability, especially when the injected fuel includes high amounts of sulphur. ${ }^{9}$

However, the EA 189 engine has a defeat device for the emission control system. The defeat device software recognises when a car is on the test stand. In test stand mode, the emission control system operates optimally. But the capacity of the emission system is reduced or completely switched off when the car is not on the test stand (see Thompson et al., 2014). VW sold 11 million cars worldwide with defeat devices (2.4 million cars in Germany). Perfidiously, especially cars that were promoted as environmentally friendly have defeat devices (Siano et al., 2017).

Before the EPA disclosed the installation of the defeat device software, only a small number of managers and EPA officers were aware of the emission test manipulations (Clemente and Gabbioneta, 2017). The nitrogen oxide emissions of cars with a defeat device exceed official limits by up-to 40 times (New York Times, 2015). Within a couple of days after the disclosure, VW stocks lost more than $20 \%$ of their value (approximately 15 billion Euros) and the CEO of VW (Martin Winterkorn) resigned (Stanwick and Stanwick, 2017). Since October 2, 2015, VW customers can check an online portal to see if their car has a defeat device. On October 30, 2015, VW submitted retrofitting plans for cars in Germany. Retrofitting is mandatory in Germany. It appears that some cars only require a software update, while other cars need a serious engine revision. VW covers the costs of retrofitting, but not necessarily increasing maintenance cost which could appear after the retrofitting.

On April 23, 2016, Der Spiegel headlines that Bosch AG (a German automotive supplier) delivered the defeat devices not only to VW, but also to many other car producers

\footnotetext{
9 An alternative technology is the selective catalytic reduction converter, which injects urea to lower the nitrogen oxide emission. Urea is sold under the brand name Ad Blue. Ad Blue has to be refilled regularly.
} 
worldwide (Spiegel, 2016). ${ }^{10}$ On October 25, 2016, US courts and VW agreed on a compensation payment of 15 billion US Dollars to US customers (about 480,000 cars with defeat device were sold in the US, Stanwick and Stanwick, 2017). This includes the costs of retrofitting, buybacks, and individual compensations between 5,000 and 10,000 US Dollars. As opposed to the US, the German rules of law do not force VW to repurchase diesel cars or to pay notable individual compensations.

The disclosure of the VW emission scandal affects the observable quality of VW diesel cars. The defeat devices could directly affect the environmental performance, power, and/or fuel consumption of the vehicle. ${ }^{11}$ Owners of manipulated cars have to visit the garage for retrofitting, which is time consuming. Moreover, the durability of the exhaust gas recirculation valve, the particulate filter, and the catalytic converter could significantly decline after retrofitting. The image of VW diesel cars declined after the disclosure of the emission manipulation scandal (Clemente and Gabbioneta, 2017, Stanwick and Stanwick, 2017). Furthermore, the emission scandal could have spillover effects on VW gasoline cars, as well as diesel cars from other producers (Clemente and Gabbioneta, 2017). For example, the image of diesel cars could decline and individuals could update their expectations about future car quality fraud revelations. We assume that the decline in observable quality is stronger for VW diesel than for other carmakers, such that the relative loss in observable quality is negative for VW diesel cars.

\section{Observed quality and used car supply}

In this section, we review Peterson and Schneider's (2016) model for used-car markets with adverse selection and sorting on durable goods markets with asymmetric information (see also

\footnotetext{
${ }^{10}$ Der Spiegel is an important weekly news magazine in Germany.

11 Busse, Knittel, and Zettelmeyer (2013) show that used-car buyers react sensitive to expected future fuel costs.
} 
Hendel and Lizzeri, 1999, 2002). This model shows how the observed car quality affects the level of adverse selection. The parameters of the model are as follows: Potential used-car sellers own one used car each. Potential used-car buyers are not endowed with any car. A potential used-car seller has the taste for quality $\theta$ that is drawn from the uniform distribution $\left[1, \theta_{H}\right]$. The cumulative distribution of potential used-car sellers with taste for quality $\theta$ is $H(\theta)=$ $\theta-1 / \theta_{H}-1$. All potential used-car buyers have the taste for quality $\theta=1$. The taste for quality of potential buyers is lower than that of potential sellers, which reflects their willingness to buy cars that have been discarded by the potential car sellers. We assume the number of potential used-car buyers exceeds the number of potential used-car sellers.

Let $Q>0$ be the observable quality of a used car. The binary variable $D$ equals one when a car has a repairable damage that is unobservable for potential car buyers and zero otherwise. We assume sellers are aware of unobservable damages. An unobservable damage appears with probability $\lambda>0$ and the costs of repair are $c>0 .{ }^{12}$ The utility of owning a car for a driver with taste $\theta$ is $\theta Q-c D$. We assume $Q-c D>0$, such that the utility from driving a car is positive and the costs of repair do not exceed the quality of the car. Drivers gain zero utility from owning a second car. Potential sellers have the option to replace their used car with a new car. The quality of a new car is $Q_{N}$ with $Q_{N}>Q$. The price of a new car is $P_{N}$. We assume the new car market is competitive, such that $Q_{N}$ and $P_{N}$ are exogenous and not influenced by the used-car market. Furthermore, we assume $\theta_{H} Q_{N}>P_{N}>Q_{N}$, which implies that it is efficient for some potential sellers to replace their used car with a new one.

Because we assume the number of potential used-car buyers exceeds the number of potential used-car sellers, the market price of used cars equals the potential buyers' reservation prices, which are proportional to the perceived car qualities. Because potential buyers of used

\footnotetext{
12 We omit observable damages to ease the notation. Peterson and Schneider (2016) show that observable damages do not change the implications of the model below.
} 
cars cannot observe the damage $D$, they form their expectations $g(Q)$ about the unobserved quality based on the observed quality. We assume rational expectations, such that $g(Q)$ equals the market share of used cars with unobservable damage by $Q$. The used-car market price is $P(Q)=Q-\operatorname{cg}(Q)$, because $\theta=1$ for potential buyers of used cars.

Potential sellers have an incentive to sell their used car and buy a new car when the utility from driving the new car, $\theta Q_{N}$, minus the price differential between the prices of the new and the used cars, $\left(P_{N}-P(Q)\right)$, exceeds the utility from driving the used car, $(\theta Q-c D)$. The utility of trade is $u(Q)=\theta\left(Q_{N}-Q\right)+c D-\left(P_{N}-Q+c g(Q)\right)$. Peterson and Schneider (2016) show that the market share of used cars with an unobservable damage equals

$$
g(Q)=\lambda+\frac{1}{2}\left(\frac{K}{c}-\sqrt{\left(\frac{K}{c}\right)^{2}-4 \lambda(1-\lambda)}\right)
$$

with $K=\theta_{H} Q_{N}-\left(\theta_{H}-1\right) Q-P_{N}$ being the utility of trade for a car owner with preference for quality $\theta_{H}$ under symmetric information. Furthermore, for sufficient small uncertainty about the condition of unobserved parts in the population, Peterson and Schneider (2016) show that

$$
\frac{\partial g(Q)}{\partial Q}>0
$$

(see proof in Online Appendix A). ${ }^{13}$ In the example of the VW emission scandal, this implies that potential buyers expect potential sellers to have incentives to bring cars with less expensive unobservable damages to the market, because, for some car owners, the manipulation decreases the utility of driving.

The marginal effect of the observed quality on the utility of trade is negative,

\footnotetext{
13 This result holds under rational expectations about the unobservable car quality. Alternatively, potential buyers could have monotone increasing believes about unobservable quality based on observable quality. For example, Kroft, Lange, and Notowidigdo (2013) show that when the observable labour market characteristics of a job candidate are higher potential employers have more positive believes about the unobserved productivity of the job candidate. Another alternative assumption would be that potential buyers do not use the observable quality to form their expectations about unobservable quality.
} 


$$
\frac{\partial u(Q)}{\partial Q}=1-\theta-c \frac{\partial g(Q)}{\partial Q}<0
$$

Accordingly, a decline in the observed quality increases the utility of trade. ${ }^{14}$ This implies that an owner of a VW diesel vehicle generates more utility of trade after the emission scandal. Potential sellers offer their car on the used car market when the utility of trade is positive. Accordingly, a decline in the observable quality increases the supply of used cars. We translate this result into an empirically testable hypothesis.

Hypothesis 1 (Supply of VW diesel cars): The supply of used VW diesel vehicles increases after the disclosure of the emission manipulation scandal.

\section{Data}

The data is collected from a large German online car advertisment platform. Private car owners and firms can offer their cars for sale on this platform. They can post several pictures and detailed descriptions of the offered car together with an asking price. Potential buyers can search for cars on this platform. When they find an appropriate car, they can contact the seller directly. The seller and potential buyer may arrange a meeting which gives the potential buyer the possibility to inspect the car. They then negotiate mutually over the transaction price, which can deviate from the asking price. ${ }^{15}$ If the seller and buyer agree on the terms of trade, then they transfer ownership of the car.

\footnotetext{
14 Additionally, the marginal effect of observable quality on transaction prices is indefinite. Under rational expectations, the increase in observable car quality can be (partly) compensated by a decrease in the expected unobservable car quality. Tadelis and Zettelmeyer (2015) find positive price effects of the disclosure of used-car quality information, even after the disclosure of bad quality. In online auctions reputation ratings are one way to signal high quality. Jin and Kato (2006) document that buyers are more likely to bid for products in eBay auctions when the seller reputation rating is high, but they are unwilling to pay higher prices.

${ }^{15}$ We do not observe transaction prices in the data.
} 


\subsection{Selection of the estimation sample}

Our sample covers the daily inflow of used cars from August 26, 2015 to April 15, 2016. The sample period ends one week before Der Spiegel headlines that the Bosch AG delivered defeat devices to many car producers worldwide (Spiegel, 2016). We analyse only used cars with diesel or gasoline engine. We omit cars with a mileage above $200,000 \mathrm{~km}$ or that are older than 20 years. These sample selection rules exclude cars with electric engines and very old cars. Table 1 shows the five different vehicle classes we consider. The inflow sample contains 1,108,566 vehicles. The sample consists mainly of compact and medium-sized vehicles. We focus on nine common carmakers in Germany. The inflow sample includes 427,286 (39\%) VW, 182,393 (16\%) BMW, 136,613 (13\%) Opel, 136,393 (12\%) Mercedes-Benz, 134,200 (12\%) Ford, 33,585 (3\%) Toyota, 25,703 (2\%) Renault, 19,585 (2\%) Peugeot, and 12,808 (1\%) Fiat vehicles.

Table 1: Vehicle classes

\begin{tabular}{|c|c|c|}
\hline Vehicle class & Considered car models & Observations \\
\hline Small & $\begin{array}{l}\text { VW Polo, Opel Corsa, Ford Fiesta, Renault Clio, } \\
\text { Peugeot 208, Fiat Punto, Toyota Yaris }\end{array}$ & $\begin{array}{l}151,346 \\
(14 \%)\end{array}$ \\
\hline Compact & $\begin{array}{l}\text { VW Golf, Mercedes A-class, BMW series 1, Opel Astra, } \\
\text { Ford Focus, Renault Megane, Peugeot 308, Toyota Auris }\end{array}$ & $\begin{array}{l}417,523 \\
(38 \%)\end{array}$ \\
\hline Medium-sized & $\begin{array}{l}\text { VW Passat, Mercedes C-class, BMW series 3, Opel } \\
\text { Insignia, Ford Mondea, Peugeot 508, Toyota Avensis }\end{array}$ & $\begin{array}{l}286,205 \\
(26 \%)\end{array}$ \\
\hline Minivan & $\begin{array}{l}\text { VW Sharan, VW Touareg, Mercedes B-class, BMW } \\
\text { series 2, Opel Zafira, Ford Galaxy, Ford C-Max, Renault } \\
\text { Scenic, Peugeot 5008, Fiat Doblo, Toyota Verso }\end{array}$ & $\begin{array}{l}148,612 \\
(13 \%)\end{array}$ \\
\hline SUV & $\begin{array}{l}\text { VW Tiguan, Mercedes GLA, Mercedes GLK, BMW X1, } \\
\text { Opel Mokka, Ford Kuga, Renault Kadjar, Toyota RAV4 }\end{array}$ & $\begin{array}{c}104,880 \\
(9 \%)\end{array}$ \\
\hline
\end{tabular}




\subsection{Descriptive Statistics}

Table 2 shows the descriptive statistics for vehicles from VW and other carmakers. The share of diesel vehicles is slightly above $50 \%$. The offered VW cars are somewhat younger than the offered vehicles from other carmakers. The average age of VW cars is three years and the average mileage is about $60,000 \mathrm{~km}$. The average age of the other carmakers is almost 4 years and the average mileage is about $67,000 \mathrm{~km} .76 \%$ of the VW cars and $61 \%$ of the vehicles from other carmakers have a full service history. Approximately $10 \%$ of the sellers offer a warranty to purchasers. In Germany, new cars undergo a general inspection after three years and must revisit the general inspection every subsequent second year. Approximately $20 \%$ of the offered cars have a new general inspection, which is valid for two years. For another $57 \%$ of the VW cars and $49 \%$ of the vehicles from other makes, the duration until the next inspection becomes due is more than one year. The share of cars offered by private sellers is approximately $10 \%$. Most car bodies are limousines or estate cars. The VW cars in the sample are more often regulated under the more recent emission standards than the vehicles from other carmakers, which reflects the younger age of the VW cars in the sample. Some German cities have environmental zones. Cars are only allowed to enter these zones when they have a special tag in the windscreen, which indicates low particulate matter emission. The lowest particulate matter emission is indicated by a green tag. Above $80 \%$ of the offered cars have a green particulate matter tag.

\subsection{Car supply over time}

Figure 1 shows the share of VW vehicles with diesel engines by month relative to all VW vehicles after the disclosure of the emission scandal. Before the disclosure, the share of VW cars with diesel engines is $53 \%$. The share of diesel cars decreases by 1 percentage point during the first two months after the disclosure of the emission scandal. Three months after the disclosure, the share of VW diesel cars increases by 2 percentage points relative to the pre- 
disclosure level. This could be a catch-up effect. The increment in the share of VW cars with diesel engines persists until 6 months after the disclosure. Seven months after the disclosure, the share of VW diesel vehicles is close to the pre-disclosure level.

Table 2: Descriptive statistics

\begin{tabular}{|c|c|c|c|c|c|}
\hline \multirow{3}{*}{ Variables } & \multicolumn{2}{|c|}{ VW vehicles } & \multicolumn{2}{|c|}{$\begin{array}{l}\text { Vehicles from other } \\
\text { carmakers }\end{array}$} & \multirow{2}{*}{$\begin{array}{c}\text { Standardised } \\
\text { Difference }\end{array}$} \\
\hline & Mean & $\begin{array}{l}\text { Std. } \\
\text { Err. }\end{array}$ & Mean & Std. Err. & \\
\hline & (1) & (2) & (3) & (4) & (5) \\
\hline Diesel & 0.54 & - & 0.52 & - & 2.98 \\
\hline Car age (in years) & 3.08 & 3.09 & 3.76 & 3.31 & 21.13 \\
\hline Mileage (in 1,000 km) & 61.3 & 52.4 & 66.6 & 51.5 & 10.2 \\
\hline Full service history & 0.76 & - & 0.61 & - & 32.03 \\
\hline Warranty & 0.08 & - & 0.11 & - & 10.42 \\
\hline New general inspection & 0.18 & - & 0.23 & - & 12.13 \\
\hline $\begin{array}{l}\text { Duration until next general } \\
\text { inspection above } 1 \text { year }\end{array}$ & 0.57 & - & 0.49 & - & 14.35 \\
\hline Private car seller & 0.10 & - & 0.13 & - & 7.32 \\
\hline \multicolumn{6}{|c|}{ Vehicle class } \\
\hline Small & 0.12 & - & 0.15 & - & 6.79 \\
\hline Compact & 0.49 & - & 0.31 & - & 36.70 \\
\hline Middle-sized & 0.19 & - & 0.30 & - & 27.85 \\
\hline Minivan & 0.12 & - & 0.14 & - & 4.49 \\
\hline SUV & 0.08 & - & 0.10 & - & 6.83 \\
\hline \multicolumn{6}{|c|}{ Car body } \\
\hline Limousine & 0.42 & - & 0.40 & - & 3.23 \\
\hline Estate & 0.26 & - & 0.29 & - & 6.95 \\
\hline Minivan & 0.10 & - & 0.08 & - & 6.16 \\
\hline SUV & 0.08 & - & 0.09 & - & 4.48 \\
\hline Small & 0.06 & - & 0.07 & - & 3.54 \\
\hline Sport & 0.03 & - & 0.05 & - & 10.73 \\
\hline Others & 0.05 & - & 0.01 & - & 22.09 \\
\hline \multicolumn{6}{|c|}{ Environmental standards } \\
\hline Below Euro 4 & 0.07 & - & 0.11 & - & 15.90 \\
\hline Euro 4 & 0.13 & - & 0.22 & - & 24.29 \\
\hline Euro 5 & 0.53 & - & 0.49 & - & 8.69 \\
\hline Euro 6 & 0.27 & - & 0.18 & - & 22.44 \\
\hline Green particulate matter tag & 0.87 & - & 0.82 & - & 14.83 \\
\hline \multicolumn{6}{|c|}{ Fuel consumption (combined) } \\
\hline Below 5 litres/100km & 0.35 & - & 0.29 & - & 12.89 \\
\hline Between 5 and 6 litres $/ 100 \mathrm{~km}$ & 0.30 & - & 0.30 & - & 0.74 \\
\hline Above 6 litres $/ 100 \mathrm{~km}$ & 0.27 & - & 0.30 & - & 7.41 \\
\hline Not reported & 0.09 & - & 0.11 & - & 7.79 \\
\hline Observations & \multicolumn{2}{|c|}{427,286} & \multicolumn{2}{|c|}{681,280} & \\
\hline
\end{tabular}

Note: See Rosenbaum and Rubin (1983) for a definition of the standardised difference. They consider an absolute standardised difference of more than 20 as being 'large'. 
Figure 1: Share of VW vehicles with diesel engine by months after the emission scandal.

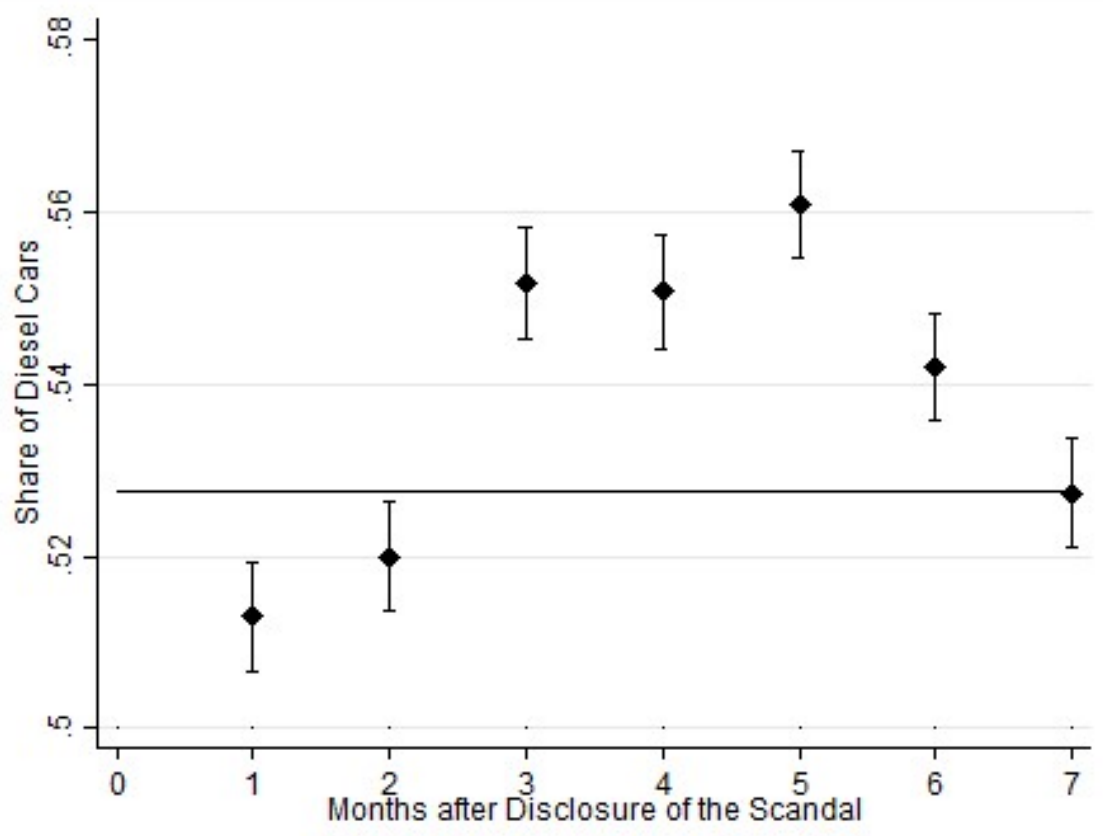

Note: The horizontal line indicates the share of VW vehicles with diesel engine before the emission scandal (52.8\%). The diamonds indicate the share of VW vehicles with diesel engines by month after the emission scandal. The capped vertical lines indicate the $95 \%$ confidence intervals of the monthly averages.

Figure 2: Share of vehicles with diesel engine for carmakers other than VW by months after the emission scandal.

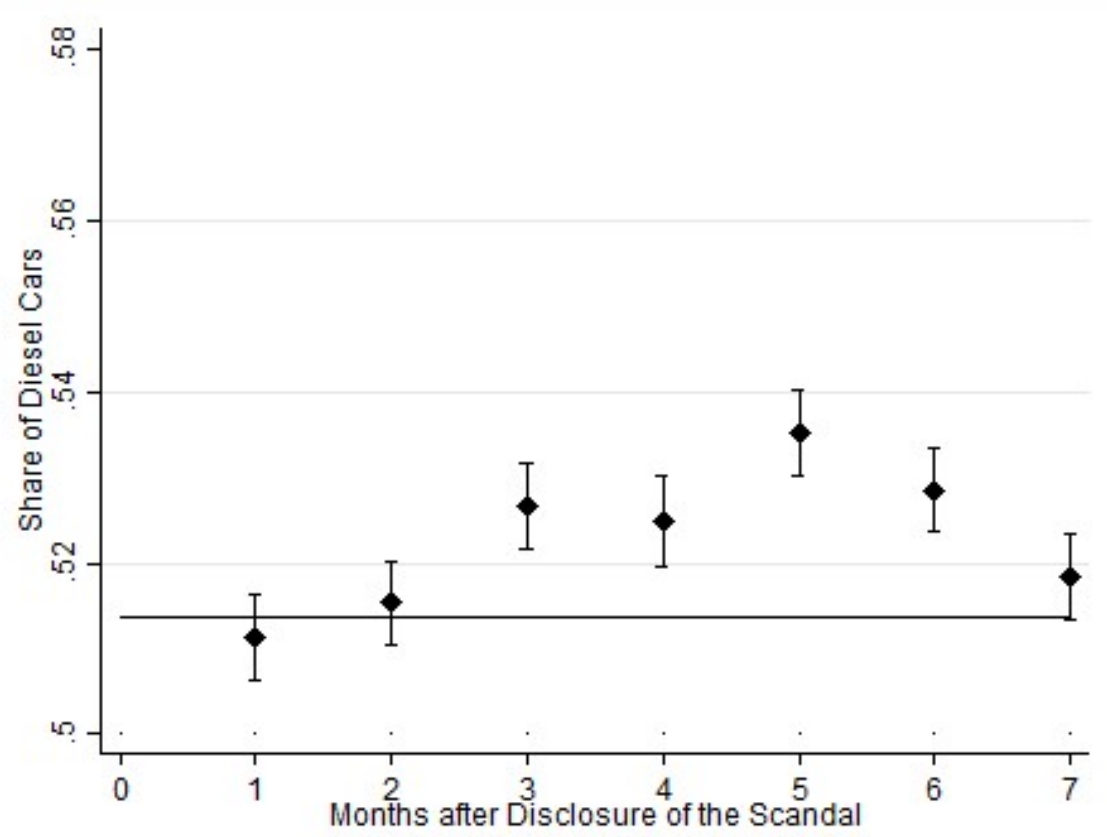

Note: The horizontal line is the share of vehicles with diesel engine for carmakers other than VW before the emission scandal (51.4\%). The diamonds indicate the share of vehicles with diesel engine for carmakers other VW by month after the emission scandal. The capped vertical lines indicate the $95 \%$ confidence intervals of the monthly averages. 
The descriptive results are consistent with the theory of adverse selection as outlined above (see Section 3), which suggests that the share of VW cars with diesel engines increases after the disclosure of the emission manipulation scandal. However, other market forces beyond the VW emission scandal could drive these results. For example, these findings could reflect time effects that are pervasive for all carmakers. Figure 2 shows the share of cars with diesel engines for carmakers other than VW. The pre-disclosure share of diesel cars is $51 \%$. Indeed, we find an increase in the share of diesel cars between months 3 and 6 after the disclosure. However, the positive effects on other carmakers are smaller than the effects on the share of VW vehicles with diesel engines. In the next section, we describe a difference-in-differences strategy to disentangle the effects of the disclosure of the emission scandal from other possible effects that may explain the rise in the share of VW diesel cars.

\section{Empirical approach}

We compare the share of diesel cars before and after the disclosure of the emission scandal and between VW and the other carmakers. The dummy variable $D, d \in\{0,1\}$, defines diesel $(D=$ 1) and gasoline cars $(D=0)$. We distinguish eight time periods in our analyses, $T, t \in$ $\{0,1,2,3,4,5,6,7\}$. The first time period $t=0$ is just before the VW emission scandal was disclosed. The other periods indicate the first seven months after the disclosure. Furthermore, we distinguish between two groups, $G, g \in\{0,1\}$. The first group includes VW cars $(g=1)$ and the second group includes cars from other carmakers $(g=0)$. The share of diesel vehicles by group and time is indicated by $E[D \mid G=g, T=t]$. We estimate

$$
\begin{aligned}
\delta_{s}=(E[D \mid G= & 1, T=s]-E[D \mid G=1, T=0]) \\
& -(E[D \mid G=0, T=s]-E[D \mid G=0, T=0]),
\end{aligned}
$$


for $s \in\{1,2,3,4,5,6,7\}$. This is a conservative estimate because not only VW diesel cars could be affected by the disclosure of the emission scandal. We assume the decline in observable quality is stronger for VW diesel cars than for cars from other carmakers. Therefore, $\delta_{s}$ is a lower bound of the impact of the emission scandal on the share of VW diesel cars.

It could be that observable car characteristics change between the groups over time. For example, sellers could bring older cars to the market. Because diesel cars tend to have a longer life-cycle than gasoline cars, this type of market behaviour would increase the share of diesel cars. To account for this, we define the conditional share of diesel cars $E[D \mid G=g, T=t, X=$ $x$ ], where $X$ contains observable car and seller characteristics. We estimate the effect of the disclosure of the emission scandal on the share of VW cars with diesel engines conditional on observable characteristics

$$
\begin{aligned}
\theta_{S}(x)=(E[D \mid G=1, T=s, X=x]-E[D \mid G=1, T=0, X=x]) \\
-(E[D \mid G=0, T=s, X=x]-E[D \mid G=0, T=0, X=x]) .
\end{aligned}
$$

The parameter $\theta_{S}(x)$ measures the effect of the emission scandal disclosure on the share of VW cars with diesel engines for cars and sellers with similar observable characteristics. We integrate the conditional effects to

$$
\theta_{S}=E_{X \mid G=1, T=0}\left[\theta_{S}(x) \mid G=1, T=0\right],
$$

which are the average effects defined for cars and sellers with characteristics that are similar to the VW group in the pre-disclosure period. Intuitively, this is the direct effect of the VW emission scandal after controlling for other possible market distortions. If we find an effect of the emission scandal on the share of diesel cars, even after controlling for a large set of important observable characteristics, then this is a strong indication for sorting.

We perform estimations in separate samples for each group and each time period. For the VW group in the pre-disclosure period, we just calculate the sample share of diesel cars. 
For the other 15 groups, we estimate the conditional moments with radius matching on the propensity score (see Lechner, Miquel, and Wunsch, 2011). ${ }^{16}$ While the propensity scores, $p(X)=\operatorname{Pr}(G=1, T=0 \mid X=x)$, are parametrically specified by probit models, the conditional expectations of the outcomes are unrestricted and thus nonparametric. The algorithm is more precise than nearest-neighbour matching due to the idea of radius matching (e.g., Dehejia and Wahba, 2002). Furthermore, the procedure uses the initial matching weights for a (weighted) regression adjustment for bias reduction in a second step (see Abadie and Imbens, 2011). ${ }^{17}$ This regression adjustment should also reduce small sample and asymptotic biases of matching. Huber, Lechner, and Wunsch (2013) investigate the finite sample properties of this algorithm along with other matching type estimators and find it to be very competitive.

We set the radius size to $90 \%$ of the $0.9^{\text {th }}$ quantile of the distance between matched treated and control observations occurring in standard nearest-neighbour matching. Inference is based on bootstrapping the respective effect 499 times and using the standard deviation of the bootstrapped effects as an estimate of the standard error of the t-statistic. Abadie and Imbens (2008) show that bootstrap-based standard errors may be invalid for matching based on a fixed number of comparison observations. However, our matching algorithm is smoother than the latter approach because it (by the nature of radius matching) uses a variable number of comparisons that are distance-weighted within the radius and, moreover, applies the regression adjustment. Therefore, the bootstrap is likely to be a valid inference procedure for the radius matching estimator used. It performs well in a large-scale (empirically based) simulation study by Bodory et al. (2016), who investigate the performance of several variance estimators in the context of propensity score based matching estimation.

\footnotetext{
16 In our opinion, the (main) advantage of matching as opposed to (widely used) linear regression based difference-indifferences approaches is the robustness to misspecification of the linear model.

17 Therefore, the estimator satisfies a so-called double robustness property, implying that it is consistent if either the propensity score or the regression model is correctly specified (e.g., Rubin, 1979, Joffe et al., 2004).
} 
Figure 3: Difference in the share of vehicles with diesel engine between $V W$ and other carmakers by months after the emission scandal.

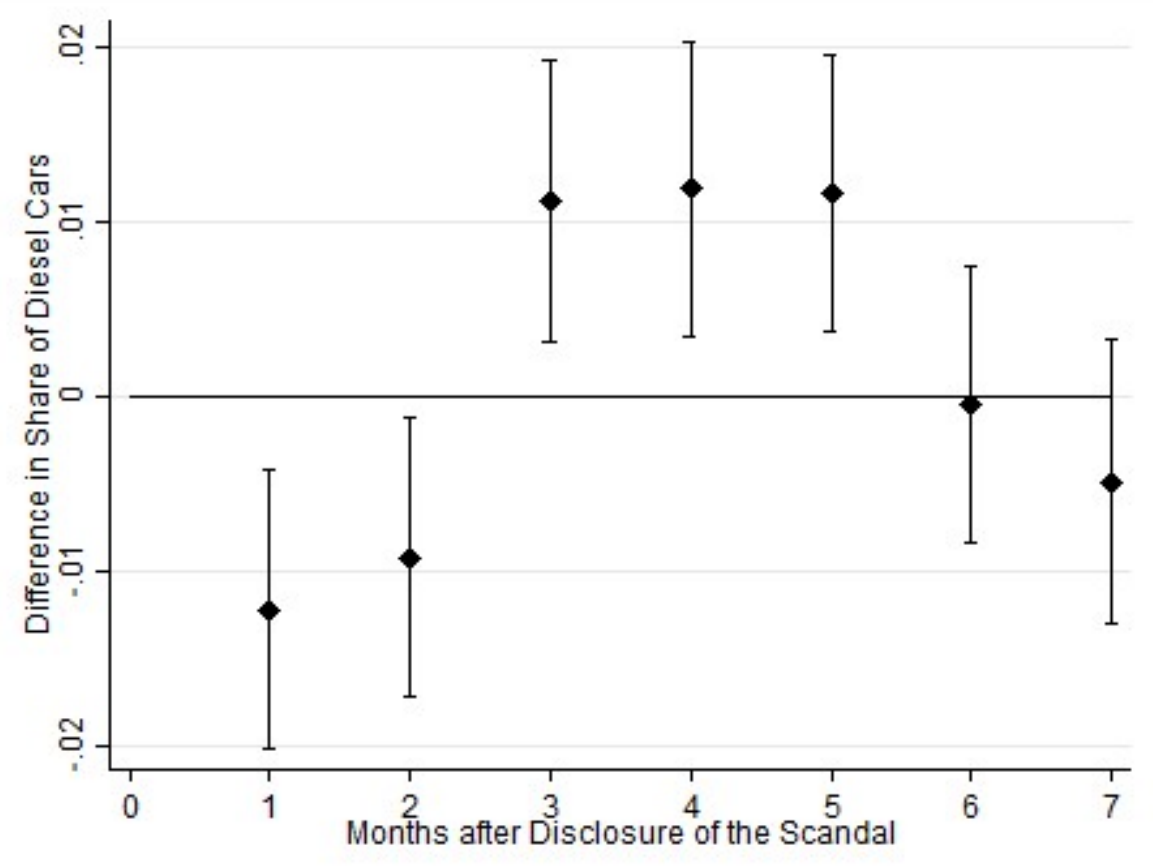

Note: The diamonds indicate the difference in the share of vehicles with diesel engine between VW and other carmakers by month after the VW emission scandal. The capped vertical lines indicate the $95 \%$ confidence intervals of the monthly averages.

\section{Results}

\subsection{Average effects}

Figure 3 documents the unconditional estimates $\delta_{s}$. They reflect the difference in the share of vehicles with diesel engine between VW and other carmakers. During the first two months after the disclosure, we find a 1 percentage point lower share of VW diesel cars; between months three and five, we find a 1 percentage point higher share of VW diesel cars. In month six and seven, the difference in the shares does not vary significantly from zero. The results could reflect delay and catch-up effects.

Figure 4 presents the results of the conditional difference-in-differences approach, $\theta_{s}$. We also control for different dummies for car age and mileage. Following the specification in Lacetera, Pope, and Sydnor (2012), we control for the first seven polynomials of mileage. We 
Figure 4: Matched difference in the share of vehicles with diesel engine between VW and other carmakers by months after the emission scandal.

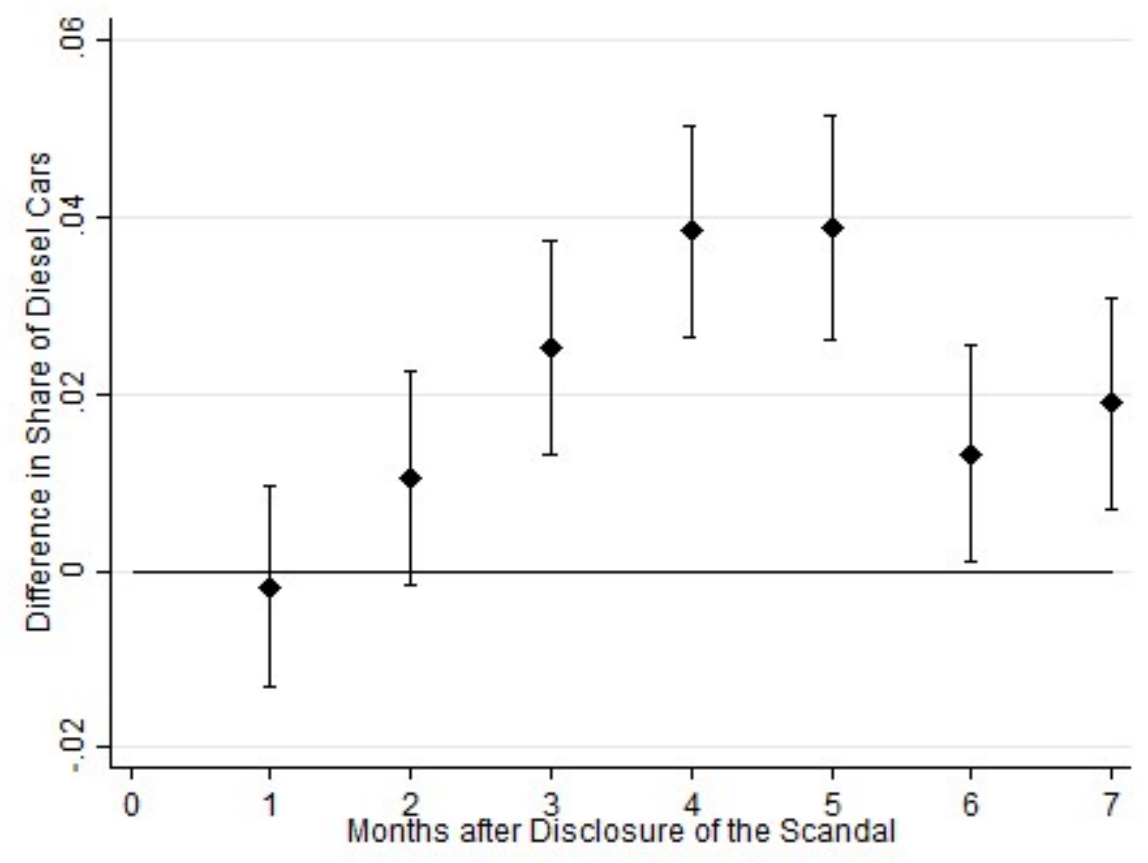

Note: The diamonds indicate the difference in the share of vehicles with diesel engine between VW and other carmakers by month after the VW emission scandal. The capped vertical lines indicate the $95 \%$ confidence intervals of the monthly averages.

include dummies for vehicle class and car body. Additionally, we include dummies for full service history, warranty, the validity of general inspection, and private seller. We control for different emission standards and fuel consumption of the offered car. Tables A.1-A.3 in Online Appendix A present the balance of the control variables before matching by group and time period. We find large imbalances, especially between the two groups of VW cars (diesel and gasoline engines) and other carmakers. Additionally, the share of Euro 6 cars within the groups increases over time.

We present the marginal effects of the propensity score estimates in Tables B.1-B.3 of Online Appendix B. The propensity score estimates serve as inputs to the matching algorithm. When performing matching, one should check for potential issues of (i) insufficient support in the propensity scores across treatment states that may result in incomparable matches as well as large matching weights of some non-treated observations with specific propensity scores, 
and (ii) imbalances in covariates after matching (due to inappropriate propensity score specifications). To account for support problems, we drop treated observation with propensity score values above the highest propensity score value in the control group. Lechner and Strittmatter (2017) show that this support procedure can improve the finite sample efficiency of the estimates. We document the distribution of the propensity scores of the observations on support for all samples in Figures C.1-C.15 in Online Appendix C. As a final specification test, we document the balancing of the control variables after matching in Tables D.1-D.3 of Online Appendix D. We find only small imbalances between groups and time periods. The standardised differences are always below 10 .

The conditional results suggest no significant effects on the share of VW diesel vehicles during the first two months after the disclosure of the emission scandal. Subsequently, we find significant positive effects on the share of VW diesel vehicles between months 3 and 7. In month 4 and 5, the share of VW diesel vehicles increases by 4 percentage points. In months 6 and 7 , the effects on the VW diesel share decline, but are still positive and significant. Accordingly, the results are robust and even more positive after we control for a large set of relevant covariates. This is a clear indication for sorting of VW diesel cars after the emission scandal. The results are coherent with Hypothesis 1 and the theory of adverse selection and sorting in durable goods markets with adverse selection (e.g., Hendel and Lizzeri, 1999). Furthermore, these results are consistent with the empirical findings of Peterson and Schneider (2016).

\subsection{Effect heterogeneity}

In this section, we estimate effect heterogeneity using the conditional difference-in-differences approach. Table 3 shows the effect of the VW emission scandal on the share of diesel cars by vehicle class. The positive effects are mainly driven by minivans and SUVs. These cars are considered heavy polluters because of their size and weight. Accordingly, the empirical results 


\begin{tabular}{|c|c|c|c|c|c|c|c|}
\hline & \multicolumn{7}{|c|}{ Month after disclosure of the emission scandal } \\
\hline & 1. & 2. & 3. & 4. & 5. & 6. & 7. \\
\hline & (1) & (2) & (3) & (4) & (5) & (6) & (7) \\
\hline \multirow[t]{2}{*}{ Small } & $-0.03 *$ & -0.002 & -0.023 & -0.007 & 0.005 & 0.015 & -0.012 \\
\hline & $(0.015)$ & $(0.016)$ & $(0.016)$ & $(0.016)$ & $(0.016)$ & $(0.015)$ & $(0.016)$ \\
\hline \multirow[t]{2}{*}{ Compact } & -0.01 & 0.002 & 0.002 & 0.0002 & -0.003 & -0.009 & $0.023^{*}$ \\
\hline & $(0.013)$ & $(0.013)$ & $(0.013)$ & $(0.014)$ & $(0.013)$ & $(0.014)$ & $(0.013)$ \\
\hline Medium- & -0.001 & 0.002 & 0.007 & 0.018 & $0.029 * *$ & 0.008 & 0.015 \\
\hline sized & $(0.011)$ & $(0.011)$ & $(0.011)$ & $(0.012)$ & $(0.011)$ & $(0.011)$ & $(0.013)$ \\
\hline \multirow[t]{2}{*}{ Minivan } & -0.009 & 0.001 & 0.026 & 0.016 & $0.053 * * *$ & $0.068 * * *$ & 0.035 \\
\hline & (0.019) & $(0.019)$ & $(0.02)$ & $(0.02)$ & $(0.02)$ & $(0.022)$ & $(0.023)$ \\
\hline \multirow[t]{2}{*}{ SUV } & 0.004 & 0.001 & 0.004 & $0.053 * *$ & $0.071 * * *$ & $0.052 * *$ & $0.101 * * *$ \\
\hline & $(0.021)$ & $(0.021)$ & $(0.022)$ & $(0.021)$ & $(0.024)$ & $(0.023)$ & $(0.024)$ \\
\hline
\end{tabular}

Note: The standard errors in parentheses are calculated with a non-parametric bootstrap (499 replications). The asterisks indicate $1 \%(* * *), 5 \%(* *)$, and $10 \%(*)$ significance levels.

are coherent for those vehicle classes which are most affected by the disclosure of the VW emission scandal. Moreover, we also find significant positive effects on the share of diesel cars for compact and medium-sized cars. Small cars are the only class for which we do not find a significant increase in the share of diesel cars. If anything, we observe a negative delay effect in the first month after the disclosure of the emission manipulation scandal.

Table 4 documents the effects on the share of VW diesel vehicles by environmental standard. Cars with defeat devices are always regulated under the Euro 5 emission standard. For VW diesel cars with an emission standard less stringent than Euro 5, we do not find any effects at all. For VW diesel cars regulated under the Euro 6 emission standard, we find negative effects six month after the disclosure. However, we observe that the share of VW diesel cars 
regulated under the Euro 5 emission standard significantly increase after the emission scandal. This suggests the positive supply effect occurs for cars with high manipulated probability, and the spillover effects to not-manipulated VW diesel are, if anything, negative. Accordingly, VW diesel car owners without defeat device (Euro 6 and below Euro 5 emission standard) do not increase their supply, possibly because they do not update their expectations about future quality fraud revelations. These results stand in contrast to the corporate security fraud literature, which finds widespread financial market reactions (Gianetti and Wang, 2016).

If an interaction between the new and used car market would bias our empirical results, then we would expect to find positive supply effects for manipulated and unmanipulated VW diesel vehicles. However, the positive supply effects occur only for cars with a high manipulation probability, which alleviates concerns about such a bias.

\section{Table 4: Effect heterogeneity by emission standard}

\begin{tabular}{lccccccc}
\hline \hline & \multicolumn{7}{c}{ Month after isclosure of the emission scandal } \\
& 1. & 2. & 3. & 4. & 5. & 6. & 7. \\
\cline { 2 - 8 } & $(1)$ & $(2)$ & $(3)$ & $(4)$ & $(5)$ & $(6)$ & $(7)$ \\
\hline Below & -0.014 & -0.018 & -0.004 & 0.006 & -0.015 & -0.005 & 0.005 \\
Euro5 & $(0.014)$ & $(0.015)$ & $(0.015)$ & $(0.016)$ & $(0.015)$ & $(0.015)$ & $(0.016)$ \\
Euro5 & 0.0001 & $0.019 * *$ & 0.01 & $0.018 * *$ & $0.038^{* * *}$ & $0.024 * * *$ & 0.004 \\
& $(0.007)$ & $(0.007)$ & $(0.007)$ & $(0.008)$ & $(0.007)$ & $(0.007)$ & $(0.008)$ \\
Euro6 & -0.036 & -0.012 & 0.01 & 0.025 & -0.03 & $-0.061 * * *$ & -0.032 \\
& $(0.024)$ & $(0.022)$ & $(0.021)$ & $(0.023)$ & $(0.022)$ & $(0.02)$ & $(0.021)$
\end{tabular}

Note: The standard errors in parentheses are calculated with a non-parametric bootstrap (499 replications). The asterisks indicate $1 \%(* * *), 5 \%(* *)$, and $10 \%(*)$ significance levels.

Table 5 reports effect heterogeneity by seller type. The share of VW diesel cars does not increase among private sellers. On the contrary, the share of VW diesel cars actually declines among private sellers. For professional car dealers, we observe a significant increase in the 
share of VW diesel cars. Only in the first month after the disclosure we find a negative delay effect. Possibly, VW diesel car owners more often engage professional car dealers as sales agent, or leasing contracts are terminated instead of extended (i.e., exploiting buyback options). The latter could occur because car leasers think the buyback price specified in the leasing contract is higher than the market price after the disclosure.

These results are also consistent with the findings of Emons and Sheldon (2009). They find adverse selection among privately and not among professionally sold cars. The adverse selection mechanism could dominate the sorting mechanism for privately sold cars, but not when professional car dealers are engaged as sales agent.

Table 5: Effect heterogeneity by seller type

\begin{tabular}{|c|c|c|c|c|c|c|c|}
\hline & \multicolumn{7}{|c|}{ Month after disclosure of the emission scandal } \\
\hline & 1. & 2. & 3. & 4. & 5. & 6. & 7. \\
\hline & (1) & (2) & (3) & (4) & (5) & (6) & (7) \\
\hline \multirow[t]{2}{*}{ Private seller } & -0.011 & $-0.03 *$ & $-0.043 * *$ & $-0.033 *$ & -0.022 & $-0.03 *$ & -0.022 \\
\hline & $(0.018)$ & $(0.017)$ & $(0.019)$ & $(0.018)$ & $(0.018)$ & $(0.017)$ & $(0.018)$ \\
\hline Professional car & $-0.017 * *$ & -0.0004 & $0.014 * *$ & $0.035 * * *$ & $0.019 * * *$ & 0.008 & $0.014 * *$ \\
\hline dealer & $(0.007)$ & $(0.007)$ & $(0.007)$ & $(0.007)$ & $(0.007)$ & $(0.007)$ & $(0.007)$ \\
\hline Professional car & -0.027 & -0.016 & 0.005 & 0.013 & $0.064 * * *$ & 0.01 & -0.011 \\
\hline dealer providing & $(0.024)$ & $(0.023)$ & $(0.025)$ & $(0.025)$ & $(0.025)$ & $(0.025)$ & $(0.024)$ \\
\hline \multicolumn{8}{|l|}{ warranty } \\
\hline Professional car & -0.011 & 0.001 & $0.015^{*}$ & $0.032 * * *$ & $0.028 * * *$ & 0.012 & $0.016^{* *}$ \\
\hline dealer not & $(0.008)$ & $(0.007)$ & $(0.008)$ & $(0.007)$ & $(0.007)$ & $(0.007)$ & $(0.007)$ \\
\hline \multicolumn{8}{|l|}{ providing } \\
\hline warranty & & & & & & & \\
\hline
\end{tabular}

Note: The standard errors in parentheses are calculated with a non-parametric bootstrap (499 replications). The asterisks indicate $1 \%(* * *), 5 \%(* *)$, and $10 \%(*)$ significance levels. 
Some professional car dealers provide warranties on offered used cars. The lower part of Table 5 shows the effect heterogeneity between professional car dealers with and without an offered warranty. For both groups, we find evidence for an increase in the share of VW diesel vehicles. However, for professional car dealers without a warranty the positive effect is much more persistent across the sample period, whereas we only find significant positive effects in the fifth month after disclosure for professional car dealers with a warranty. Accordingly, professional car dealers who do not offer warranties are mainly responsible for the increase in the share of VW diesel cars after the emission scandal. Guajardo, Cohen, and Netessine (2016) argue that a decline in product quality increases the positive effect of warranties on car demand. Hence, the lower number of cars offered with warranties could disproportionally decrease the demand for used VW diesel cars after the disclosure of the emission scandal.

\section{Conclusions}

We use a classical model for adverse selection and sorting in durable goods markets with asymmetric information to derive an empirically testable hypothesis about the relation between observable product quality and supply. This model predicts that the supply of used cars increases after a decline in the observable quality. We test this prediction with a large data set collected from an online used-car market. We exploit the quasi-experimental decline in the observable quality of VW diesel vehicles after the disclosure of the VW emission manipulation scandal. The empirical approach is based on a conditional difference-in-differences method, which is carried-out with semi-parametric matching estimators. Our findings are coherent with the predictions of the theoretical model and correspond to previous empirical findings of the literature (e.g., Hendel and Lizzeri, 1999, Peterson and Schneider, 2016). The supply of VW diesel cars increases after the disclosure of the VW emission manipulation scandal. Furthermore, we show that the supply increases only for VW diesel cars that have a high probability of having been manipulated. This is evidence against the updating of expectations 
about future quality frauds revelations. Finally, professional car dealers are less likely to offer warranties on VW diesel vehicles after the disclosure of the emission scandal.

\section{References}

Abadie, A., G.W. Imbens (2008): “On the Failure of the Bootstrap for Matching Estimators", Econometrica, 76 (6), 1537-1557.

Abadie, A., G.W. Imbens (2011): "Bias-Corrected Matching Estimators for Average Treatment Effects", Journal of Business and Economic Statistics, 29 (1), 1-11.

Adams, C., L. Hosken, P. Newberry (2011): "Vettes and Lemons on eBay", Quantitative Marketing and Economics, 9 (2), 109-127.

Akerlof, G. (1970): “The Market for Lemons: Qualitative Uncertainty and the Market Mechanism", Quarterly Journal of Economics, 84 (3), 488-500.

Alexander, C.R. (1999): “On the Nature of the Reputational Penalty for Corporate Crime: Evidence", Journal of Law and Economics, 42 (S1), 489-526.

Bodory, H., L. Camponovo, M. Huber, M. Lechner (2016): “The Finite Sample Performance of Inference Methods for Propensity Score Matching and Weighting Estimators", SEPS Discussion Paper, No. 2016-04.

Bond, E. (1982): “A Direct Test of the 'Lemons' Model: The Market for Used Pickup Trucks”, American Economics Review, 72 (4), 836-840.

Bond, E. (1984): “Test of the Lemons Model: Reply”, American Economic Review, 74 (4), 801804

Busse, M.R., C.R. Knittel, F. Zettelmeyer (2013): “Are Consumers Myopic? Evidence from New and Used Car Purchases”, American Economic Review, 103 (1), 220-256.

Clemente, M., C. Gabbioneta (2017): "How Does the Media Frame Corporate Scandals? The Case of German Newspapers and the Volkswagen Diesel Scandal“, Journal of Management Inquiry, forthcoming.

Cook, L., N. McArdle, D. Warner (2006): “An Overview of California’s Low Emission Vehicle Program and Efforts to Implement It in Maryland and Other States", Department of Legislative Services, Office of Policy Analysis, Annapolis, Maryland. 
Dehejia, R.H., S. Wahba (2002): "Propensity-Score-Matching Methods for Nonexperimental Causal Studies", Review of Economics and Statistics, 84 (1), 151-161.

Emons, W., G. Sheldon (2009): “The Market for Used Cars: New Evidence of the Lemons Phenomenon", Applied Economics, 41 (22), 2867-2885.

Engers, M., M. Hartmann, S. Stern (2009): “Are Lemons Really Hot Potatoes?”, International Journal of Industrial Organization, 27 (2), 250-263.

EPA (2015): "Notice of Violation" sent by EPA to Volkswagen Group of America, Inc (18 September 2015).

European Commission (1991): "Council Directive 91/441/EEC", Official Journal of the European Communities, No. L 242/1 (30.08.1991).

European Commission (2007): "Regulation (EC) No 715/2007 of the European Parliament and of the Council", Official Journal of the European Communities, No. L 171/1 (29.06.2007).

Gande, A., C.M. Lewis (2009): "Shareholder Initiated Class Action Lawsuits: Shareholder Wealth Effects and Industry Spillovers", Journal of Financial and Quantitative Analysis, 44 (4), 823-850.

Genesove, D. (1993): “Adverse Selection in the Wholesale Used Car Market", Journal of Political Economy, 101 (4), 644-665.

Giannetti, M., T.C. Wang (2016): "Corporate Scandals and Household Stock Market Participation", Journal of Finance, 71 (6), 2591-2636.

Gilligan, T. (2004): "Lemons and Leases in the Used Business Aircraft Market", Journal of Political Economy, 112 (5), 1157-1180.

Guajardo, J.A., M.A. Cohen, S. Netessine (2016): "Service Competition and Product Quality in the U.S. Automobile Industry”, Management Science, 62 (7), 1860-1877.

Hendel, I., A. Lizzeri (1999): “Adverse Selection in Durable Goods Markets”, American Economic Review, 89 (5), 1097-1115.

Hendel, I., A. Lizzeri (2002) “The Role of Leasing Under Adverse Selection”, Journal of Political Economy, 110 (1), 113-143.

Huber, M., M. Lechner, C. Wunsch (2013): “The Performance of Estimators Based on the Propensity Score”, Journal of Econometrics, 175 (1), 1-21. 
Jin, G.Z., A. Kato (2006): "Price, Quality, and Reputation: Evidence from an Online Field Experiment”, RAND Journal of Economics, 37 (4), 983-1005.

Jin, G.Z., P. Leslie (2003): “The Effect of Information on Product Quality: Evidence from Restaurant Hygiene Grade Cards", Quarterly Journal of Economics, 108 (2), 409-451.

Joffe, M.M., T.R. Ten Have, H. Feldman, S.E. Kimmel (2004): "Model Selection, Confounder Control, and Marginal Structural Models: Review and New Applications", American Statistician, 58 (4), 272-279.

Johnson, J., M. Waldman (2003): "Leasing, Lemons, and Buybacks", RAND Journal of Economics, 34 (2), 247-265.

Johnson, J., H. Schneider, M. Waldman (2014): "The Role and Growth of New-Car Leasing: Theory and Evidence", Journal of Law and Economics, 57 (3), 140-154.

Johnson, W.C., W. Xie, S. Yi (2014): "Corporate Fraud and the Value of Reputations in the Product Market", Journal of Corporate Finance, 25, 16-39

Karpoff, J.M., J.R. Lott, E. Wehrly (2005): “The Reputational Penalties for Environmental Violations: Empirical Evidence", Journal of Law and Economics, 68 (2), 653-675.

Kraftfahrtbundesamt (2015a): "Fahrzeugzulassungen (FZ) Besitzumschreibungen von Kraftfahrzeugen und Kraftfahrzeuganhängern“", Monatsergebnisse Dezember 2015, FZ 9.

Kraftfahrtbundesamt (2015b): "Fahrzeugzulassungen (FZ) Neuzulassungen von Kraftfahrzeugen und Kraftfahrzeuganhängern“", Monatsergebnisse Dezember 2015, FZ 8.

Kroft, K., F. Lange, M.J. Notowidigdo (2013): "Duration Dependence and Labor Market Conditions: Evidence from a Field Experiment”, Quarterly Journal of Economics, 128 (3), $1123-1167$.

Lacetera, N., D.G. Pope, H. Sydnor (2012): "Heuristic Thinking and Limited Attention in the Car Market”, American Economic Review, 102 (5), 2206-2236.

Lechner, M., R. Miquel, C. Wunsch (2011): “Long-Run Effects of Public Sector Sponsored Training in West Germany”, Journal of the European Economic Association, 9 (4), 742 784.

Lechner, M., A. Strittmatter (2017): "Practical Procedures to Deal with Common Support Problems in Matching Estimation“, Econometric Reviews, forthcoming.

Lewis, G. (2011): “Asymmetric Information, Adverse Selection, and Online Disclosures: The Case of eBay Motors", American Economic Review, 101 (4), 1535-1546. 
Luca, M., G. Zervas (2016): "Fake It Till You Make It: Reputation, Competition, and Yelp Review Fraud”, Management Science, 62 (12), 3412-3427.

New York Times (2015): "Volkswagen Says 11 Million Cars Worldwide Are Affected in Diesel Deception”, 23.09.2015.

Palmrose, Z.-V., V.J. Richardson, S. Scholz (2004): "Determinants of Market Reactions to Restatement Announcements", Journal of Accounting and Economics, 37 (1), 59-89.

Peterson, J., H. Schneider (2014): “Adverse Selection in the Used - Car Market: Evidence from Purchase and Repair Patterns in the Consumer Expenditure Survey", RAND Journal of Economics, 45 (1), 140-154.

Peterson, J., H. Schneider (2016): "Beautiful Lemons: Adverse Selection in Durable-Goods Markets with Sorting”, Management Science, forthcoming.

Rosenbaum, P., D.B. Rubin (1983): "The Central Role of the Propensity Score in Observational Studies for Causal Effects", Biometrika, 70 (1), 41-55.

Rubin, D.B. (1979): "Using Multivariate Matched Sampling and Regression Adjustment to Control Bias in Observational Studies", Journal of the American Statistical Association, 74 (2), 318-328.

Siano A., A. Vollero, F. Conte, S. Amabile (2017): "More than Words: Expanding the Taxonomy of Greenwashing after the Volkswagen Scandal”, Journal of Business Research, $71,27-37$.

Spiegel (2016): "Bosch hat Schummelsoftware nicht nur an VW geliefert" Issue 17, 23.04.2016.

Stanwick, P., S. Stanwick (2017): "Volkswagen Emissions Scandal: The Perils of Installing Illegal Software", International Review of Management and Business Research, 6 (1), 1824.

Stiglitz, J.E. (1987): “The Causes and Consequences of the Dependence of Quality on Price”, Journal of Economic Literature, 25 (1), 1-48.

Tadelis, S., F. Zettelmeyer (2015): "Information Disclosure as a Matching Mechanism: Theory and Evidence from a Field Experiment", American Economic Review, 105 (2), 886-905.

Thompson, G.J., D.K. Carder, M.C. Besch, A. Thiruvengadam, H.K. Kappanna (2014): “InUse Emissions Testing of Light-Duty Diesel Vehicles in the United States", Final Report prepared for the International Council on Clean Transportation (ICCT). 
Yang L., V. Franco, A. Campestrini, J. German, P. Mock (2015): "NOx Control Technologies for Euro 6 Diesel Passenger Cars: Market Penetration and Experimental Performance Assessment", Whitepaper, National Academies of Sciences, Engineering, and Medicine. 